\title{
"Historias de vida profesional y prácticas pedagógicas en la enseñanza de las artes visuales, una mirada reflexiva"
}

\author{
Patricia Raquimán Ortega
}

Miguel Zamorano Sanhueza

\section{Resumen}

Este articulo explora la relevancia de la narración personal en torno a la experiencia profesional docente que se vincula a la educación artística. Se mencionan los métodos de indagación basados en la entrevista en profundidad de carácter narrativo como formas de comprender de manera profunda las relaciones entre vida profesional y biografía personal. Las historias de vida constituyen un enfoque que ha permitido indagar en la dimensión personal y profesional, en los modos como los profesores(as) construyen y desarrollan su práctica profesional en la enseñanza de las Artes Visuales considerando el componente contextual, pensado como un factor clave para la comprensión de este proceso.

Palabras clave: Historia de vida profesional, Artes Visuales, Educación Artística.

\section{Abstract}

This article explores the relevance of personal narrative around teaching professional experience linked to artistic education. Inquiry methods based on the in-depth narrative interview are mentioned as ways to understand the relationships between professional life and personal biography. Life stories are approaches which allow to investigate into the personal and professional dimension, in ways which teachers construct and develop their professional practices in teaching visual arts, considering the contextual component, thought as a key factor to understand this process.

Keywords: Professional life story, visual arts, artistic education. 
Este articulo se enmarca en la investigación: Historias de vida profesional, prácticas pedagógicas desde el contexto. Las voces de los titulados de Pedagogía en Artes Visuales ${ }^{1}$; se ha considerado los relatos de vida profesional, por este motivo se sitúa desde el enfoque Comprensivo, en un Paradigma netamente Cualitativo.

Cuando se abordan investigaciones sobre la práctica pedagógica, la tendencia es considerar miradas externas al cotidiano de la práctica del profesor(a) en ejercicio, desarrollando principalmente enfoques descriptivos-estructuralistas. El enfoque sobre las historias de vida profesional ha sido una opción en la recuperación de la subjetividad que construye el actor, desde sus propios relatos y experiencias.

La narración en el campo educativo establece un desafío muy relevante, que permite implicarse en un diálogo con el docente, develando el significado de su relato en relación a su desempeño profesional. Para llevar a cabo esta tarea, se debe considerar que el texto será resultado de una co-construcción entre el yo-narrado, el narrador y el locutario, o receptor de la historia.

No se debe olvidar que el sujeto que narra, además de poder hablar y actuar, tiene la capacidad de unificar la visión de su vida (en este caso profesional) dentro de la historia que cuenta, en la que se reconoce como un personaje protagonista. Es por esto que develar la transformación del discurso en acontecimiento, es reconocer que el discurso no sólo acontece, sino que también significa. El esfuerzo, a partir de aquí, es comprender el discurso como una historia que proporciona un sentido.

Las instituciones y las prácticas sociales tienen historias, y la comprensión de estas prácticas se asume con frecuencia en forma de un relato que da cuenta de sus procesos. Los relatos profesionales reconocen que las prácticas existen en el tiempo y cambian en la medida en que éste transcurre, junto a las condiciones de cada contexto. Se caracterizan por situarse en un pasado que puede ser revisado comprensivamente, para determinar diferentes dimensiones de acción y reflexión. Así, los esfuerzos por entender los relatos acerca de las prácticas pedagógicas implementadas en el aula, permiten definir los propósitos que han tenido los profesores(as) para actuar, conocer cómo lo han hecho, qué decisiones han tomado y bajo qué circunstancias.

En este contexto, las voces de los profesores(as), que relatan sus prácticas como posibilidad de entender la realidad, generan la construcción de un modo de comprensión y expresión de la vida profesional, en la cual se hace presente su voz.

Debido a que la actividad educativa es una acción práctica que acontece en situaciones específicas, guiada por determinadas intenciones, parece - como lo ponen de manifiesto los maestros y maestras cuando nos hablan de sus clases - que los relatos y el modo narrativo es una forma, al menos tan válida como la para-

|||||||||||||||||||||||||||||||||||||||||||||||||||||||||||

1 Proyecto en curso FIPEA 19-16 financiado por la Dirección de Investigación de la Universidad Metropolitana de Ciencias de la Educación; duración 2 años (2016-2017). 
digmática, de comprender y expresar la enseñanza (BOLÍVAR, 2002, p.7).

Rescatar la dimensión personal del oficio de enseñar es, también, un modo de “oponerse al profesorado anónimo, sin nombre e impersonal” (BOLÍVAR et al., 2001, p.52). La narrativa permite que se releve la experiencia, la complejidad, las relaciones y la singularidad de cada acción.

Los escenarios profesionales en donde se dan lugar experiencias educativas ligadas a la producción artística y a sus formas de ser comprendidas, se encuentran determinados por múltiples variables. Estas influencias inciden en las modalidades de apropiación del currículum pensado en dichos contextos. Las variables abarcan un sinnúmero del componentes que se conectan directamente con el campo disciplinar en el que están insertas. En el caso de las artes visuales, es ya sabida la ampliación técnica, temática y conceptual que ha expandido la conexión entre artes y diferentes áreas de conocimiento disciplinar (BORGDORFF, p. 44-63). Las implicancias de esta permeabilización de los bordes disciplinares se están verificando actualmente en los modos en que cada protagonista del escenario educativo, especialmente los profesores(as), exponen el conocimiento de las diferentes áreas.

Sin embargo, los aprendizajes, como se ha discutido con profusión en las últimas décadas, están lejos de producirse sobre una tabula rasa, ya que cada profesor(a) posee una cronología vital que se engarza con un ámbito socio-cultural y con un conjunto de atributos personales de tipo más subjetivo. Es decir, una biografía situada en diversos espacios de la experiencia que configuran una continuidad a partir de la cual surge un relato explicativo de estos procesos. Teniendo en cuenta esto, la historia vital de cada persona determina su manera de relacionarse con el conocimiento de la asignatura de artes visuales y con las diversas modalidades de aproximación a diferentes temas y procesos.

Del mismo modo, quienes desarrollan una guía o intentan estructurar el aprendizaje -los profesores- poseen una biografía propia que incide en las decisiones, acercamientos, estrategias y concepciones sobre su propio desempeño en la asignatura de artes visuales. Así, la investigación que se organiza alrededor del análisis de las percepciones sobre la propia vida, en este caso, de los docentes, cobra importancia para determinar sus modos de percibirse a sí mismos. "Los métodos biográficos describen, analizan e interpretan la vida de una persona, para comprenderla en su singularidad o como parte de un grupo" (MALLIMACI y GIMÉNEZ, 2006, p.175).

La historia de vida de las personas tiene, sin duda, un papel muy relevante si pensamos que es esta historia la que contiene las posibilidades electivas de profesores(as). Ello incide, finalmente, en los distintos momentos del proceso de enseñanza y aprendizaje. La percepción del propio tiempo vital se encuentra determinada por los lugares o instituciones que se encargaron de dar una formación, los juicios de valor generados en los diferentes contextos de vida, las concepciones de arte descubiertas o heredadas, etc. Cada episodio aporta una situación concreta de experiencia y articula cierto tipo de respuestas 
al medio, lo que explica, en gran medida, las acciones e interpretaciones del escenario en el que los sujetos se encuentran inscritos.

Los contenidos biográficos se encuentran dentro de un conjunto de focos complejos de indagación, pues no se trata de descripciones objetivas, homogéneas y clausuradas en términos cronológicos o interpretativos. Por el contrario, la complejidad del relato de vida radica precisamente en su alto nivel de subjetividad, su apertura a la revisión, su interpretación situada en diferentes escenarios temporales, con un carácter diacrónico que interpreta desde un tiempo presente, pero con una proyección en el futuro (SMITH, 1994, citado en MALLIMACI y GIMENEZ, 2006, p.190).

Cada persona posee un relato cuya autoría individual es intransferible en relación a su auto percepción. Desde un punto de vista psicológico que tome en consideración el relato como una forma de auto-comprensión, se podría decir que

No importa si el relato verbal que la persona hace frente a la pregunta ¿quién eres? es verídico o no, si se contradice o no, lo importante es cómo él se contesta a sí mismo, y cómo ese contestarse se traduce en acciones, muchas de las cuales son contradictorias entre sí, o en comportamientos explícitos o implícitos (ZLACHEVSKY, 1998, p.4).

En otras palabras, en el relato de sí el factor de veracidad no es tan relevante como el de discursividad que se produce en relación a la historia vivida.

En definitiva, se trata de considerar el relato biográfico, dado por diferentes protagonistas, como un lugar en donde se produce un intercambio de sentidos interpretados por un protagonista. Esto tiene relación con la conciencia de sí mismo en relación a un escenario concreto, así como las percepciones subjetivas que se producen hacia esos mismos ámbitos en términos de sus componentes potencialmente significativos. ¿Cuál sería esta carga de significado en el caso de esta investigación? Fundamentalmente, el modo a través del cual los profesores(as) de artes visuales perciben su medio, se auto-perciben y generan una reflexión acerca de su propio desempeño, que posibilitaría generar indagaciones con respecto a su forma de construir el conocimiento disciplinar.

Considerando lo anterior, la historias de vida permiten profundizar una indagación que puede producir una comprensión de las estructuras profundas constitutivas de las conductas docentes, relacionadas con los aspectos más subjetivos de la enseñanza. En este punto, se permite indagar en la dimensión personal y profesional, en los modos como los profesores(as) construyen y desarrollan su práctica profesional en la enseñanza de las artes visuales considerando el componente contextual, pensado como un factor clave para la comprensión de este proceso.

Los puntos de vista acerca de la educación artística que se han dado especialmente en las últimas décadas, han adquirido una mayor densidad discursiva, lo cual constituye un potencial soporte para generar acercamientos relevantes en lo que se refiere a la com- 
prensión de cómo se construye realidad en el cotidiano de la sala de clases.

Las concepciones inter, intra y transculturales, como también la exposición de problemáticas contingentes, son parte de un potencial imaginario colectivo situado en la educación, tanto a nivel primario como secundario. Por ejemplo, la condición humana y la experiencia parecen determinar nuevas interrogantes en relación a las inquietudes que pueden darse en el terreno de lo educacional (EISNER \& DAY, 2004). Este cambio, que se da especialmente a contar del momento en que el pensamiento de lo cualitativo abre el campo para fenómenos más heterogéneos, repercute directamente en la experiencia artística. La diversidad de esta elaboración situada en la imagen permite pensar ciertos fenómenos y producir obras que se mueven en diferentes perspectivas, explicándose a partir de ellos la complejidad de la experiencia artística visual y su dificultad para ser no sólo pensada, sino experimentada en el contexto escolar actual.

En este contexto, se entiende por narrativa, "la cualidad estructurada de la experiencia entendida y vista como un relato; por otra parte, las pautas y formas de construir sentido, a partir de acciones temporales personales, por medio de la descripción y análisis de los datos" (BOLÍVAR, 2002, p.5). La narración permite comprender la complejidad que poseen las experiencias de los individuos, los conflictos y dilemas en sus vidas. Se valora al sujeto como poseedor de respuestas que puede llegar a ayudar a la comprensión de la realidad, según Gadamer, lo que caracteriza a los seres humanos es la capacidad de entenderse a través de la conversación, su proyecto originario "se centra en la exploración hermenéutica del ser histórico tal como se expresa en la tradición del lenguaje" (FREIRE, RETAMAL \& SEPÚLVEDA, 2005, p.56).

En muchas ocasiones la generación de un conocimiento artístico de baja calidad proviene de un aprendizaje deficitario (EFLAND, FREEDMAN \& STUHR, 2003). Por este motivo, resulta imprescindible penetrar en el significado de los conceptos críticos que pueden ser abordados por la enseñanza de las Artes Visuales, no considerándolos como contenidos inamovibles y fijos, que puedan resultar en esquemas mentales o procedimientos técnicos ingenuos o superficiales (EFLAND et al, 2003), sino en construcciones complejas, con desafíos tanto expresivos como analíticos en la comprensión de las artes y en sus implicancias en diferentes contextos.

La identificación del arte como producción construida desde la cultura, la superación del concepto de progreso lineal y temporal, el reconocimiento de la diferencia, la democratización de las artes, la polisemia y la adaptación al contexto constituyen características sobresalientes dentro del enfoque epistemológico posmoderno (EFLAND et al, 2003, p.29-32). Esto ha generado la necesidad de volver a pensar en las formas de concebir la labor docente en cuanto a sus modos de abordar la complejidad de la producción artística visual de hoy y el contexto en que se sitúan sus estudiantes. Ante este escenario, las artes visuales permiten dialogar directamente con el conocimiento artístico en escenarios escolares, pensado como el cruce que se da entre educación, arte y producción visual actual. El diálogo parece ser privilegiado, pues se trata de una noción que se construye desde un encuentro con el profesor(a) y su práctica pedagógica cotidiana. 
Considerando lo anterior, el proceso de enseñanza y aprendizaje se encuentra expuesto a tensiones que, justamente, intensifican el reconocimiento de lo complejo, de lo ambiguo y de la alteridad.

Esta investigación pretende expandir la noción del proceso de enseñanza y aprendizaje de las Artes Visuales, verificando su impacto en productos y prácticas concretas de profesores(as) que se desempeñan en diferentes dependencias administrativas, que permitan una construcción de su cotidiano y una reflexión de cómo el contexto en que se desenvuelven junto con sus alumnos y la experiencia artística, se transforma en una posibilidad de comprensión y transformación social.

\begin{abstract}
¿Por qué habría de preocuparse uno por aspectos aparentemente triviales del comportamiento social? Pasar junto a alguien en la calle o intercambiar unas palabras con un amigo pueden parecer actividades menores y carente de interés, cosas que hacemos infinidad de veces al día sin pensar en ellas. Sin embargo, el estudio de estas formas de INTERACCION SOCIAL, aparentemente significantes es de enorme importancia para la sociología y, lejos de carecer de interés, es una de las áreas más absorbentes de la investigación sociológica. Existen dos razones para que sea tan importante. En primer lugar, las rutinas cotidianas, con sus casi constantes interacciones con los demás, estructuran y conforman lo que hacemos. Al estudiarlas podemos aprender mucho de nosotros como seres sociales y de la misma vida social. Nuestras vidas están organizadas en torno a la repetición de pautas de comportamiento parecidas día tras día, semana tras semana, mes tras mes y año tras año [...]. En segundo lugar, el estudio de la interacción social en la vida cotidiana arroja luz sobre instituciones y sistemas sociales más amplios que de hecho, dependen de las pautas de interacción social que seguimos en el día a día (GIDDENS, 1998, p.106-107).
\end{abstract}

En ese contexto, la enseñanza de las artes visuales se convierte en un espacio de encuentro de culturas distintas, donde la cultura dominante, en algunos casos occidental o académica, se siente como una única posibilidad de entendimiento. Es importante reconocer que los lugares tienen sus propias manifestaciones personales, culturales, históricas, de trayectoria personal, familiar y de comunidades. Se debe reconocer que cada protagonista construye su cultura desde sus propias historias e interacciones, lo cual lleva a reconocer ese espacio personal, íntimo, que se puede fortalecer desde lo que somos, fuimos y podemos llegar a ser. Cultura individual versus cultura dominante que invisibiliza a los individuos.

Cuando se piensa en cultura, en muchos casos se parte del prejuicio de enriquecer una comunidad con miradas externas a ella, siendo un discurso tan avasallador que se enmudece a cada individuo y su cotidiano. Es importante cambiar la mirada y preguntar- 
se desde otro lugar ¿cómo se releva el mundo interior como una manifestación cultural que nos representa?

Por este motivo, se ha evidenciado la necesidad de levantar líneas de pensamiento en cuanto a la acción docente y su relación con sus prácticas pedagógicas que se enlacen a la experiencia de las Artes Visuales, ya sea en cuanto a su sentido, sus significados implícitos o explícitos, o bien sus relaciones inter y transdisciplinares, desde referentes locales y contextuales. La investigación en el área de la educación artística desde esta perspectiva es aún tarea pendiente;

Los países iberoamericanos necesitan impulsar la investigación en educación artística, sistematizar experiencias, desarrollar y compartir metodologías y didáctica, elementos que sin duda constituyen campos abiertos, de cuyo avance depende la posibilidad de la comprensión, sistematización y proyección de sus posibilidades dentro de los sistemas educativos en los niveles básico, medio superior y superior (JIMÉNEZ, AGUIRRE y PIMENTEL, 2009, p.12).

Esto constituye una oportunidad de propiciar la reflexión ligada a la creación artística y, por sobre todo, una manera de comprender la sensibilidad como un pensamiento que sobrepasa el análisis racional y la habilidad localizada en un manejo instrumental de la representación. Lo anterior implica un intento por lograr, desde los(as) profesores(as), una comprensión de sus propias concepciones de arte, identificar prácticas docentes que rescaten el pensamiento complejo por sobre la identificación de componentes formales, relevar métodos de trabajo que propongan visiones problematizadoras sobre la realidad y evidenciar estrategias de enseñanza que permitan considerar el arte como una expresión de la vida para dar a los participantes un reconocimiento a una mirada más diversa, dando la oportunidad de lo local, los pequeños relatos, miradas desde el contexto. "Gran parte de la realidad es pura construcción social: el dinero, la propiedad, el matrimonio, las funciones de género, los sistemas económicos, la pobreza...las artes contienen representaciones de la realidad social" (EFLAND, et al 2003, p.124). En este contexto el arte cumple una función de construir la realidad (EFLAND, et al, 2003) y por ese motivo es de suma importancia valorar las construcciones que se dan en el espacio íntimo de sala de clases cuando un profesor(a) considera el contexto próximo del alumno como una posibilidad de reflexión y construcción desde su propia realidad y con ello, desde su propio relato.

A partir de la crisis que vive la racionalidad técnica, la narración permite abrir nuevas posibilidades de comprensión para así captar la riqueza de las experiencias y develar el conocimiento que nace de la propia acción. Los relatos de vida permiten acceder a la vida cotidiana de los profesores, sus vivencias en contextos institucionales determinados, captar su voz y convertirlos en el centro de la construcción de conocimiento y renovar la enseñanza de las artes visuales. 


\section{Bibliografia}

BOLÍVAR, A. (2002). ¿De nobis ipsis silemus?: Epistemología de la investigación biográfico-narrativa en educación. Revista Electrónica de Investigación Educativa, 4 (1). Consultado el 10 de Agosto de 2006 En: http://redie.uabc.uabc.mx/vol4no1/contenido-bolivar. html.

BOLÍVAR, A., DOMINGO, J. \& FERNÁNDEZ, M. (2001). La investigación biográficanarrativa en educación. Enfoque y metodología. Madrid: Editorial La Muralla, S.A.

BORGDORFF, Henk, “The production of knowledge in artistic research”, en Biggs, Michael y Karlsson, Henrik (2012). The Routledge Companion to Research in the Arts. London: Routledge.

EFLAND, A., FREEDMAN, K. \& STUHR, P. (2003). La educación en el arte posmoderno. Barcelona, España: Paidós.

EISNER, E. \& DAY, M. (2004 b). Handbook of Research and Policy in Art Education. London, New Jersey: Lawrence Erlbaum Associates, Publishers.

FREIRE, A., RETAMAL, J. \& SEPÚLVEDA, R. (2005). La aventura epistemológica de nuestra propia comprensión. Una mirada desde la Pedagogía. Chile: Ediciones Universidad Católica Silva Henríquez.

GIDDENS, A. (1998) Sociología. Madrid: Alianza.

JIMÉNEZ, L., AGUIRRE, I., PIMENTEL, L. (2009) Educación artística, cultura y ciudadanía. Madrid, España: OEI y Fundación Santillana.

MALLIMACI, F. y GIMENEZ, V. (2006) “Historia de vida y métodos biográficos” en Vasilachis de Gialdino, Irene et al. Estrategias de Investigación Cualitativa. Barcelona: Gedisa.

ZLACHEVSKY. (1998). “¿Es posible ser coherente?”, en Revista Terapia Psicológica, Santiago de Chile, Año XVI, Volumen VII (1), No 29. Disponible en https://www.academia. edu/14236216/_ES_POSIBLE_SER_COHERENTE 